\title{
N-3 Long-Chain Polyunsaturated Fatty Acids Prevent Excessive Fat Deposition in Adulthood in a Mouse Model of Postnatal Nutritional Programming
}

\author{
ANNEMARIE OOSTING, DIANE KEGLER, GÜNTHER BOEHM, HARM T. JANSEN, BERT J. M. VAN DE HEIJNING,
} AND ELINE M. VAN DER BEEK

\begin{abstract}
Danone Research-Centre for Specialised Nutrition [A.O., D.K., H.T.J., B.J.M.H., E.M.B.], 6704 PH Wageningen, The Netherlands; Danone Research [G.B.], D-61381 Friedrichsdorf, Germany; Department of Paediatrics [G.B.], Sophia Children's Hospital, Erasmus
\end{abstract} University, 3015 GJ Rotterdam, The Netherlands

\begin{abstract}
This study investigates whether improved quality of nutrients during early postnatal life has effects on adult metabolic profile and body composition in a murine model of nutritional programming. Male offspring of $\mathrm{C} 57 \mathrm{Bl} / 6 \mathrm{j}$ dams received a diet containing $21 \%$ energy (En\%) as fat of either $100 \%$ vegetable oils [control (CTRL)] or $80 \%$ vegetable oils/20\% tuna fish oil [rich in n-3 long-chain polyunsaturated fatty acids (n-3 LCP)] from postnatal day (PN) 2 to 42. Subsequently, mice of both experimental groups were switched to a western style diet (WSD; 21 En\% fat, high saturated fatty acid [FA] content, and cholesterol) until dissection at PN98. Body composition was analyzed by dual x-ray absorptiometry during the WSD challenge. Results showed that a n-3 LCP-rich diet during postnatal life not only reduced fat accumulation by $\sim 30 \%$ during the WSD challenge from PN42 to 98 ( $p<0.001)$ but also led to a healthier plasma lipid profile, healthier plasma glucose homeostasis, and less hypertrophic adipocytes compared with CTRL. This study shows that postnatal nutrition has programming effects on adult body composition and metabolic homeostasis. In addition, it emphasizes that moderate alterations in fat quality during early postnatal life considerably affect adult metabolic health. (Pediatr Res 68: 494499, 2010)
\end{abstract}

$\mathrm{O}$ verweight has become a major medical and public health problem over the past decades. The prevalence of (abdominal) obesity and impaired glucose tolerance with concomitant morbidity and mortality has risen to epidemic proportions $(1,2)$ and increasingly starts to emerge at an early age $(3,4)$. This exponential increase cannot be explained solely by an increase in fat and energy intake (5). It is thought to be associated with a shift toward increased dietary $n-6$ and decreased $n-3$ fatty acid (FA) intake. Linoleic acid (LA; C18:2n-6) and $\alpha$-linolenic acid (ALA; C18:3n-3) are essential FAs (EFAs) from the n-6 and n-3 FA series, respectively, which cannot be synthesized de novo by animals and have to be obtained from dietary sources. ALA is substrate for biosynthesis of n-3 long-chain polyunsaturated fatty acids (n-3 LCP), such as docosahexaenoic acid (DHA; C22:6n-3) and eicosapentaenoic acid (EPA; C20:5n-3), which

Received May 7, 2010; accepted July 17, 2010

Correspondence: Annemarie Oosting, Danone Research, Bosrandweg 20, 6704 PH Wageningen, The Netherlands; e-mail: annemarie.oosting@danone.com

H.T.J. is currently at TNO Nutrition and Food Research Institute, 3700 AJ Zeist, The Netherlands. have a biological role as membrane constituent and lipid mediator. Conversely, LA can be converted to arachidonic acid (ARA; C20:4n-6) (6). N-6 LCP ARA and its eicosanoid metabolites have the capacity to directly stimulate adipogenesis through activation of peroxisome proliferator-activated receptors delta and gamma. As a consequence, a shift toward increased dietary n-6 FA intake, especially in periods of growth and development, would lead to increased fat mass (FM) gain $(7,8)$.

Epidemiological and experimental evidence indicates that cardiometabolic risk factors originate not only from established genetic and contemporary lifestyle factors but also from nutritional and environmental disturbances during prenatal and early postnatal life $(9,10)$. An increased risk of cardiovascular and metabolic disorders based on such disturbances can be either aggravated or ameliorated by early postnatal environment $(11,12)$. Indeed, accelerated postnatal growth in preterm infants is associated with increased adiposity at term (13) and higher BMI and FM in young adults (14). The same was shown for small-for-gestational-age infants in whom postnatal catch-up growth was correlated with higher total FM and more abdominal body fat at age 4 y compared with appropriate-for-gestational-age infants (15).

Most established experimental models concerning dietary programming have a strong focus on fetal development and malnutrition by means of maternal energy or protein restriction or high-fat feeding (16-18). The role of macronutrient quality, as opposed to quantity, is still largely unknown and merits investigation. In addition, the extent to which early nutrition during infancy and childhood can affect adult metabolic health during exposure to a moderate obesogenic environment remains elusive.

In adult human and animal subjects, dietary n-3 LCP improve insulin sensitivity and counteract dyslipidemia by reducing ectopic triglyceride (TG) accumulation in liver and

Abbreviations: ARA, arachidonic acid; BW, body weight; CRL, crownrump length; CTRL, control; DEXA, dual energy x-ray absorptiometry; DHA, docosahexaenoic acid; FA, fatty acids; FM, fat mass; HOMA-IR, homeostasis model assessment of insulin resistance; LCP, long-chain polyunsaturated fatty acids; PN, postnatal day; TG, triglycerides; WAT, white adipose tissue; WSD, western style diet 
muscle (19), increasing skeletal muscle glucose utilization (20), increasing mitochondrial and peroxisomal $\beta$-oxidation (21), and reducing body weight (BW) gain and adiposity (22). Thus, direct effects of n-3 LCP in adulthood on glucose homeostasis, lipid metabolism, and adiposity have been well established. However, data on nutritional programming by postnatal n-3 LCP are restricted to beneficial effects on brain development (23) and allergy prevention (24), whereas data on BW or composition are scarce. A limited number of experimental programming studies have investigated sustained metabolic effects of EFA during gestation and lactation $(25,26)$. The capacity to convert ALA in DHA is rather limited in humans compared with rodents and even more limited in infants, suggesting that dietary ALA during periods of rapid growth in early life may not suffice, and dietary n-3 LCP are required to secure healthy development. This may explain the increased DHA synthesis capacity in women and dams during gestation and lactation (6).

This study investigated whether a moderate change in dietary fat quality during infancy and childhood affects metabolic health and body composition when subjected to an obesogenic adult environment. With a murine model, we examined the programming effect of postnatal n-3 LCP on metabolic response to a western style diet (WSD) in adulthood.

\section{METHODS}

Animals and study design. All experimental procedures were approved by the Animal Experimental Committee DEC-Consult, Bilthoven, The Netherlands, and complied with the principles of laboratory animal care. Mice were housed in Macrolon type 2 cages and kept on a 12/12 h light/dark cycle [light on $0600 \mathrm{~h}=$ Zeitgeber time (ZT) $0 \mathrm{~h}]$ in a temperature- and humiditycontrolled room $\left(21 \pm 2^{\circ} \mathrm{C}\right.$ and $50 \pm 5 \%$, respectively). Food and water were available ad libitum during the entire experimental protocol. Male and female C57Bl/6j mice were obtained from the Centre of Laboratory Animals of Wageningen University and Research Centre (Wageningen, The Netherlands) and time-mated. After birth, litters were culled to four male and two female pups per dam on postnatal day (PN) 2 and assigned to either an early control (CTRL) or n-3 LCP diet (Research Diet Services, Wijk bij Duurstede, The Netherlands). After weaning, male pups were housed in pairs and continued with their respective diets until PN42, a period corresponding with infancy and childhood in humans. All male pups changed to the WSD during adolescence and adulthood from PN42 until dissection on PN98.

A separate experiment comparing body composition development of male C57B1/6j mice fed with WSD or a standard rodent chow (AIN93) from PN42 to 98 showed that especially FM increased because of the WSD. FM increased by $67 \%$, whereas lean body mass (LBM) decreased by $8 \%$ in WSD-fed mice compared with the AIN93-fed mice (unpublished data). These data confirm that the relatively mild WSD indeed affects body composition.

Experimental diets. All diets (Table 1) were semisynthetic, consisted of AIN93-G ingredients (Research Diet Services), and contained 21\% energy (En\%) as fat, $17 \mathrm{En} \%$ protein, and $62 \mathrm{En} \%$ carbohydrates. The composition of mineral and vitamin mix is according to American Institute of Nutrition formulation of AIN93G purified diets for laboratory rodents (27).

The early CTRL diet contained a mixture of vegetable oils with a FA composition similar to human infant milk formula with a total $n-6 / n-3$ ratio of 5.67. The early $n-3$ LCP diet contained the same vegetable oil blend but $20 \%$ was substituted with tuna fish oil resulting in a 3.7-fold lower total n-6/n-3 ratio compared with the CTRL diet. The WSD contained $21 \mathrm{En} \%$ fat, consisting of $11 \mathrm{En} \%$ lard, $10 \mathrm{En} \%$ vegetable oils, and $0.1 \mathrm{En} \%$ cholesterol, resulting in a high saturated FA content and a relative high $n-6 / n-3$ ratio compared with both early diets.

In a separate study, milk samples were withdrawn from dams on PN7 $(n=$ 5/group) using an adjusted human lactation pump $10 \mathrm{~min}$ after oxytocin injection $(0.3 \mathrm{~mL}$ s.c., $1 \mathrm{IU} / \mathrm{mL}$; Eurovet) to confirm increased $\mathrm{n}-3 \mathrm{LCP}$ in milk due to early diet. In addition, FA composition of erythrocytes of the male
Table 1. Colposition of the experimental diets

\begin{tabular}{lccc}
\hline & \multicolumn{2}{c}{ Early postnatal diet } & \\
\cline { 2 - 3 } & CTRL & $\mathrm{n}-3$ LCP & WSD \\
\hline Sodium caseinate, (g/kg) & 200 & 200 & 200 \\
Cornstarch, (g/kg) & 450 & 450 & 450 \\
Maltodextrin (DE19), (g/kg) & 150 & 150 & 150 \\
Vegetable oil blend*, (g/kg) & 100 & 80 & 50 \\
Tuna fish oil, (g/kg) & - & 20 & - \\
Lard, (g/kg) & 0 & 0 & 50 \\
Saturated fatty acids, (En\%) & 8.88 & 7.74 & 8.94 \\
Mono unsaturated fatty acids, (En\%) & 8.26 & 7.82 & 9.02 \\
Poly unsaturated fatty acids, (En\%) & 3.89 & 4.28 & 2.82 \\
LA, C18:2n-6 (En\%) & 3.16 & 2.54 & 2.54 \\
ALA, C18:3n-3 (En\%) & 0.56 & 0.27 & 0.28 \\
ARA, C20:4n-6 (En\%) & - & 0.06 & - \\
EPA, C20:5n-3 (En\%) & - & 0.26 & - \\
DHA, C22:6n-3 (En\%) & - & 1.07 & - \\
C18 n-6/n-3 & 5.67 & 9.44 & 9.15 \\
Total n-6 (En\%) & 3.16 & 2.60 & 2.54 \\
Total n-3 (En\%) & 0.56 & 1.67 & 0.28 \\
Total n-6/n-3 & 5.67 & 1.55 & 9.15 \\
Cellulose (Vitacel L 600-20), (g/kg) & 50 & 50 & 50 \\
Mineral mix, (g/kg) & 35 & 35 & 35 \\
Vitamin mix, (g/kg) & 10 & 10 & 10 \\
Choline bitartrate, (g/kg) & 2.5 & 2.5 & 2.5 \\
L-cystein, (g/kg) & 3 & 3 & 3 \\
Tert-butylhydroquinone, (g/kg) & 0.014 & 0.014 & 0.014
\end{tabular}

* Mixture of oils, among others canola oil, sunflower oil, coconut oil, and palm oil.

pups was analyzed at weaning as index for the effect of early diet on tissue of the offspring $(28,29)$.

Dual energy $x$-ray absorptiometry (DEXA). On PN42, 70, and 98, FM and LBM were measured by DEXA scan under general anesthesia (isoflurane/ $\mathrm{N}_{2} \mathrm{O} / \mathrm{O}_{2}$ ) using a PIXImus imager (GE Lunar, Madison, WI). In addition, crown-rump length (CRL) and $\mathrm{BW}$ were measured.

Blood sampling and dissection. On PN98, mice were put under terminal anesthesia (isoflurane/ $\mathrm{N}_{2} \mathrm{O} / \mathrm{O}_{2}$ ) for final DEXA scan and dissection after $4 \mathrm{~h}$ fasting during the light phase (from $0730 \mathrm{~h} ; \mathrm{ZT}=1.5 \mathrm{~h}$ onward). Blood samples were taken via cardiac puncture and collected in $\mathrm{K}_{3}$ EDTA-coated 1-mL microtubes (Greiner Bio-one, Alphen a/d Rijn, The Netherlands). Plasma was obtained by centrifugation at $1350 \times \mathrm{g}$ for $12 \mathrm{~min}$ at $4^{\circ} \mathrm{C}$ (Biofuge fresco, Heraeus, Hanau, Germany) and stored at $-80^{\circ} \mathrm{C}$. Liver, pancreas, and epididymal, perirenal, and inguinal white adipose tissue (WAT) depots were collected and weighed. Epididymal WAT depots were split and either fixed overnight and embedded in paraffin or snap frozen and stored at $-80^{\circ} \mathrm{C}$ until further analysis.

Histological and biochemical analyses of adipose tissue. Embedded epididymal WAT was sectioned $(7 \mu \mathrm{m})$ and stained with hematoxylin and eosin. Images were captured by using an Axioplan 2 Zeiss microscope (Carl Zeiss, Weesp, The Netherlands) and a Sony DXC-950P videocamera (Sony, Badhoevedorp, The Netherlands). Six representative sections and four images per section were used to assess average adipocyte surface area and size distribution per animal with analySIS software (Soft imaging system, Münster, Germany). For DNA analysis, frozen epidydimal WAT samples were ground in liquid $\mathrm{N}_{2}$, incubated in $\mathrm{AL}$ buffer (Qiagen Benelux, Venlo, The Netherlands) and proteinase K (Qiagen Benelux B.V.) for $2 \mathrm{~h}$ at $56^{\circ} \mathrm{C}$, and subsequently vortexed and lysed in nuclisens lysis buffer (BioMerieux, Boxtel, The Netherlands) for $10 \mathrm{~min}$ at $37^{\circ} \mathrm{C}$. DNA was extracted using a NucliSens easyMAG automated nucleic acid extraction system (BioMerieux) and incubated with a fluorescent nucleic acid stain for double-stranded DNA (Quant-iT dsDNA HS reagent; Invitrogen, Merelbeke, Belgium). Fluorescence was quantified at 502/523 nm using a Qubit fluorometer (Invitrogen). In addition, WAT homogenate was freeze-dried for colorimetrical analysis of TG content (GPO grinder kit, Sigma Chemical Co. Aldrich, Zwijndrecht, The Netherlands). TG/DNA ratio and total DNA per WAT depot (DNA/mg tissue $\times$ total depot weight) were calculated from these analyses.

Plasma analyses. Fasting plasma total cholesterol (TC; cholesterol liquicolor CHOD-PAP; Instruchemie, Delfzijl, The Netherlands), TG (GPO trinder method, Sigma Chemical Co. Aldrich), FFA (NEFA-C method; Wako Chemicals, Neuss, Germany), and glucose (GOD-PAP method; Roche diag- 
nostics, Almere, The Netherlands) were measured colorimetrically and analyzed with a microplate imaging system (Bio-Rad Laboratories Inc., Hercules, CA). Total adiponectin was determined using a mouse adiponectin ELISA kit (Linco Research, Billerica, MA). Plasma insulin, leptin, monocyte chemoattractant protein (MCP)-1, total plasminogen activator inhibitor (tPAI)-1, IL-6, $\mathrm{TNF} \alpha$, and resistin were measured simultaneously using a mouse serum adipokine lincoplex kit (Linco Research). Samples, standards, and quality control were prepared according to manufacturers' protocol, and fluorescence was measured using a Bio-Plex 200 Luminex instrument (Bio-Rad Laboratories). Homeostasis model assessment of insulin resistance (HOMA-IR) was calculated from fasting plasma glucose and insulin [glucose $(\mathrm{mmol} / \mathrm{L}) \times$ insulin $(\mathrm{pmol} / \mathrm{L}) / 22.5]$ as an indirect measure of insulin sensitivity.

Statistical analysis. Statistical analyses were performed using SPSS 15.0.1 (SPSS Benelux, Gorinchem, The Netherlands). Variables were checked for Gaussian distribution with the Shapiro-Wilkes test. Levene's test for equality of variance was used to estimate the probability that treatment groups had different variances. Direct and programming effects of experimental diet (CTRL, n-3 LCP) on BW, food intake, and development of body composition were analyzed using a repeated-measures ANOVA. Post hoc analyses were performed on significant Diet $\times$ Time interactions by univariate ANOVA of PN42, 70, and 98, separately. The $t$ test was used to analyze the effect of experimental diets on body composition at PN42 and to analyze effects on WAT weight, organ weight, erythrocyte and milk FA composition, frequency distribution of adipocyte cell surface area, average adipocyte cell surface area, WAT TG, WAT DNA, TG/DNA ratio, and plasma parameters at PN98. Data are presented as mean \pm SEM unless otherwise indicated. Differences were considered significant at $p<0.05$.

\section{RESULTS}

Analysis of milk FA composition at PN7 confirmed a change in FA supply to the pups during lactation. A marked increase of $\mathrm{n}-3 \mathrm{LCP}\left(t_{8}=-24.935, p<0.001\right)$ and decrease of LCP n-6/n-3 ratio $\left(t_{8}=9.037, p<0.001\right)$ were observed in milk of n-3 LCP dams. FA composition of erythrocytes in male pups at weaning was changed accordingly (Table 2).

During early dietary intervention from PN2 to 42, a similar increase $\left(F_{(8,32)}=839.063, p<0.001\right)$ in BW was observed in both experimental groups $\left(F_{(8,32)}=0.419, p=0.901\right.$; data not shown). Food intake did not differ between experimental groups during early diet intervention $\left(F_{(1,11)}=0.018, p=\right.$ 0.895; data not shown).

Body composition, however, did differ at PN42 because of the dietary intervention during the preceding $40 \mathrm{~d}$ (Table $3)$, with a lower absolute $\operatorname{FM}\left(F_{(1,22)}=12.746, p=0.002\right)$ and lower relative FM (\%FM; $\left.F_{(1,22)}=10.011, p=0.004\right)$ of n-3 LCP mice compared with CTRL mice. Other body composition parameters at that time, such as $\operatorname{CRL}\left(F_{(1,22)}=\right.$ $0.287, p=0.598)$, BW $\left(F_{(1,22)}=1.798, p=0.194\right)$, and $\operatorname{LBM}\left(F_{(1,22)}=0.046, p=0.831\right)$ were unaffected by early dietary intervention.

Between PN42 and 98, during which all mice were switched from their respective early diets to the WSD, no differences in BW gain were observed between CTRL and n-3 LCP mice $\left(F_{(1,22)}=0.265, p=0.612\right.$; data not shown). Food intake was also similar between experimental groups during WSD challenge $\left(F_{(1,11)}=0.299, p=0.182\right)$. In addition, food intake within each experimental group did not change with transition from early diet to $\mathrm{WSD}\left(F_{(1,23)}=0.623, p=0.439\right)$.

During WSD challenge, CRL, BW, LBM, FM, and \%FM increased significantly over time (Table 3 ). Development of CRL, BW, and LBM was similar between experimental groups. However, both absolute and relative FM accumulations were reduced in n-3 LCP mice compared with CTRL mice. This was confirmed by a significant Time $\times$ Diet interaction for FM and \% FM $\left(F_{(2,44)}=6.756, p<0.01\right.$ and $F_{(2,44)}=3.586, p<0.05$, respectively). Subsequent post hoc analysis showed that FM and \%FM were significantly lower in n-3 LCP mice on PN42 (FM: $p<0.01$; \%FM: $p<0.01$ ) and PN98 (FM: $p<0.001$; \%FM: $p<0.001$ ).

In line with the observed lower total body FM at PN98 in n-3 LCP mice, epididymal $\left(t_{(22)}=2.585, p=0.017\right)$ and inguinal $\left(t_{(6)}=2.775, p=0.032\right)$ fat depot weights were lower in n-3 LCP mice compared with CTRL mice. Weight of organs involved in metabolism such as liver $\left(t_{(22)}=1.365\right.$, $p=0.186)$ and pancreas $\left(t_{(14)}=-0.662, p=0.519\right)$ were similar between the two experimental groups (Table 4).

At PN98, CTRL mice had a greater number of large epididymal adipocytes compared with n-3 LCP mice (Fig. 1). This was confirmed by a higher amount of DNA per milligram WAT $\left(t_{(22)}=2.846, p=0.012\right)$ and lower TG/DNA ratio $\left(t_{(22)}=-2.949, p=0.007\right)$ in epididymal WAT of n-3 LCP

Table 2. Milk FA composition $(\mathrm{n}=5 /$ group) at PN7 and erythrocyte FA composition of male pups $(C T R L: \mathrm{n}=9 ; n$-3 LCP: $\mathrm{n}=6)$ at weaning (\% of total FA)

\begin{tabular}{|c|c|c|c|c|}
\hline & \multicolumn{2}{|c|}{ Milk } & \multicolumn{2}{|c|}{ Erythrocytes } \\
\hline & CTRL & n-3 LCP & CTRL & n-3 LCP \\
\hline LA, C18:2n-6 & $7.37 \pm 0.56$ & $6.89 \pm 0.29$ & $7.94 \pm 0.15$ & $6.97 \pm 0.10^{*}$ \\
\hline ALA, C18:3n-3 & $0.58 \pm 0.04$ & $0.29 \pm 0.01 *$ & $0.21 \pm 0.01$ & $0.09 \pm 0.01 *$ \\
\hline ARA, C20:4n-6 & $0.67 \pm 0.08$ & $0.52 \pm 0.03$ & $14.02 \pm 0.19$ & $7.61 \pm 0.13^{*}$ \\
\hline EPA, C20:5n-3 & $0.17 \pm 0.01$ & $0.27 \pm 0.02 \dagger$ & $0.47 \pm 0.01$ & $2.43 \pm 0.04^{*}$ \\
\hline DHA, C22:6n-3 & $0.23 \pm 0.01$ & $1.63 \pm 0.03 *$ & $6.13 \pm 0.06$ & $12.61 \pm 0.14 *$ \\
\hline Saturated fatty acids & $51.20 \pm 3.53$ & $48.57 \pm 0.56$ & $42.29 \pm 0.10$ & $44.71 \pm 0.21 *$ \\
\hline Mono unsaturated fatty acids & $37.44 \pm 2.75$ & $39.54 \pm 0.56$ & $21.25 \pm 0.09$ & $19.60 \pm 0.13 *$ \\
\hline Poly unsaturated fatty acids & $11.36 \pm 0.85$ & $11.89 \pm 0.43$ & $34.50 \pm 0.10$ & $33.63 \pm 0.23 *$ \\
\hline$n-6$ LCP & $2.50 \pm 0.29$ & $2.25 \pm 0.09$ & $18.47 \pm 0.16$ & $10.44 \pm 0.16^{*}$ \\
\hline n-3 LCP & $0.59 \pm 0.03$ & $2.27 \pm 0.06^{*}$ & $7.62 \pm 0.06$ & $16.05 \pm 0.20 *$ \\
\hline LCP $n-6 / n-3$ & $4.17 \pm 0.35$ & $0.99 \pm 0.03 *$ & $2.42 \pm 0.03$ & $0.65 \pm 0.02 *$ \\
\hline Total n-6 & $10.01 \pm 0.83$ & $9.20 \pm 0.39$ & $26.59 \pm 0.11$ & $17.47 \pm 0.24 *$ \\
\hline Total n-3 & $1.20 \pm 0.04$ & $2.57 \pm 0.06^{*}$ & $7.92 \pm 0.06$ & $16.17 \pm 0.20^{*}$ \\
\hline Total n-6/n-3 & $8.34 \pm 0.64$ & $3.58 \pm 0.12 *$ & $3.36 \pm 0.03$ & $1.08 \pm 0.02 *$ \\
\hline
\end{tabular}

Data are presented as mean \pm SEM.

$* p<0.01$ compared with CTRL.

$\dagger p<0.01$ compared with CTRL. 
Table 3. Development of body composition during WSD challenge (PN42 to 98) of mice fed CTRL diet or n-3 LCP $\operatorname{diet}(\mathrm{n}=12 /$ group $)$

\begin{tabular}{|c|c|c|c|c|c|c|}
\hline & \multicolumn{3}{|c|}{ CTRL } & \multicolumn{3}{|c|}{ n-3 LCP } \\
\hline & PN42 & PN70 & PN98 & PN42 & PN70 & PN98 \\
\hline Crown-rump length (mm) & $73.0 \pm 0.8$ & $75.9 \pm 0.6$ & $78.5 \pm 0.8$ & $73.5 \pm 0.5$ & $76.3 \pm 0.8$ & $79.5 \pm 0.7$ \\
\hline Body weight $(\mathrm{g})$ & $22.4 \pm 0.3$ & $27.5 \pm 0.4$ & $31.0 \pm 0.7$ & $21.8 \pm 0.4$ & $27.3 \pm 0.4$ & $29.2 \pm 0.6$ \\
\hline Lean body mass (g) & $18.1 \pm 0.3$ & $21.2 \pm 0.4$ & $22.6 \pm 0.5$ & $18.2 \pm 0.3$ & $21.8 \pm 0.4$ & $23.2 \pm 0.4$ \\
\hline Fat mass $(\mathrm{g})$ & $4.3 \pm 0.2$ & $6.3 \pm 0.3$ & $8.43 \pm 0.3$ & $3.5 \pm 0.1 *$ & $5.5 \pm 0.3$ & $5.98 \pm 0.4 \dagger$ \\
\hline$\%$ Fat mass & $19.2 \pm 0.9$ & $22.8 \pm 0.9$ & $27.1 \pm 0.7$ & $15.8 \pm 0.5^{*}$ & $20.2 \pm 1.1$ & $20.4 \pm 1.2 \dagger$ \\
\hline
\end{tabular}

$* p<0.01$ compared with CTRL.

$\dagger p<0.001$ compared with CTRL.

Table 4. Average weight of WAT depots and organs at PN98 of mice fed with CTRL or $n-3$ LCP diet from PN2 to $42 *$

\begin{tabular}{lcc}
\hline & CTRL & $\mathrm{n}-3 \mathrm{LCP}$ \\
\hline WAT & & \\
Epididymal (mg) & $968.2 \pm 93.1$ & $632.5 \pm 90.5 \dagger$ \\
Perirenal (mg) & $110.8 \pm 11.9$ & $80.9 \pm 12.5$ \\
Inguinal (mg) & $628.3 \pm 72.9$ & $357.3 \pm 65.0 \dagger$ \\
Liver (g) & $1.32 \pm 0.1$ & $1.20 \pm 0.1$ \\
Pancreas (mg) & $92.4 \pm 17.9$ & $115.5 \pm 30.0$ \\
\hline
\end{tabular}

$* n=12 /$ group and $n=4$ /group for inguinal WAT.

$\dagger p<0.05$ compared with CTRL.

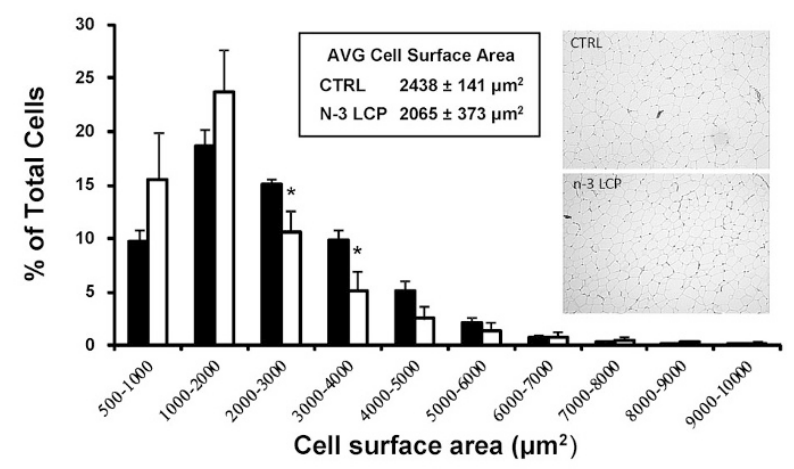

Figure 1. Frequency distribution of adipocyte cell surface area from the epididymal fat depot at PN98; CTRL $(\square ; n=8)$ vs n-3 LCP $(\square ; n=5)$ during early neonatal life; ${ }^{*} p<0.05$ compared with CTRL.

mice compared CTRL. TG content per milligram WAT and total DNA per WAT depot were comparable between both groups (Table 5).

Plasma fasting TC and TG seemed to be lower in n-3 LCP mice compared with CTRL mice, but these differences did not reach significance (TC: $t_{(21)}=2.061, p=0.054$; TG: $t_{(21)}=$ $1.355, p=0.190$ ). In addition, no difference was observed in fasting plasma FFA in n-3 LCP and CTRL mice. Most plasma adipokines including MCP-1, adiponectin, TNF $\alpha$, tPAI-1, and resistin were similar between both the treatment groups (Table 5). However, in accordance with the observed reduction in FM, plasma leptin was significantly reduced $\left(t_{(20)}=2.351\right.$, $p=0.029)$ in $\mathrm{n}-3$ LCP mice compared with CTRL mice. In addition, plasma IL-6 was significantly higher in n-3 LCP mice $\left(t_{(21)}=-3.126, p=0.008\right)$. With regard to glucose homeostasis, n-3 LCP mice had lower fasting glucose levels $\left(t_{(21)}=2.313, p=0.031\right)$ and a tendency to have lower fasting insulin $\left(t_{(21)}=2.062, p=0.052\right)$, ultimately resulting in a lower HOMA-IR index $\left(t_{(20)}=2.227, p=0.045\right)$ compared with their CTRL-fed counterparts.
Table 5. Average fasting plasma parameters and DNA and TG content of epididymal WAT depot at PN98 of mice fed with CTRL or $n-3$ LCP diet from PN2 to 42 *

\begin{tabular}{lcc}
\hline & CTRL & n-3 LCP \\
\hline Plasma & & \\
Adipokines & & \\
Adiponectin $(\mathrm{mg} / \mathrm{L})$ & $8.381 \pm 0.114$ & $8.157 \pm 0.390$ \\
Leptin $(\mu \mathrm{g} / \mathrm{L})$ & $4.971 \pm 0.797$ & $2.600 \pm 0.638 \dagger$ \\
Resistin $(\mu \mathrm{g} / \mathrm{L})$ & $4.059 \pm 0.251$ & $4.028 \pm 0.409$ \\
MCP-1 $(\mathrm{ng} / \mathrm{L})$ & $9.555 \pm 1.342$ & $11.806 \pm 0.769$ \\
tPAI-1 $(\mu \mathrm{g} / \mathrm{L})$ & $1.837 \pm 0.169$ & $2.350 \pm 0.412$ \\
TNF $\alpha(\mathrm{ng} / \mathrm{L})$ & $4.265 \pm 0.154$ & $4.289 \pm 0.296$ \\
IL-6 $(\mathrm{ng} / \mathrm{L})$ & $6.357 \pm 0.826$ & $16.455 \pm 3.123 \dagger$ \\
Insulin & & \\
Glucose $(\mathrm{mmol} / \mathrm{L})$ & $16.509 \pm 0.710$ & $13.609 \pm 1.008 \dagger$ \\
Insulin $(\mathrm{pmol} / \mathrm{L})$ & $114.623 \pm 26.314$ & $56.920 \pm 9.525$ \\
HOMA-IR $[(\mathrm{mmol} / \mathrm{L} \cdot$ & $89.108 \pm 22.851$ & $35.437 \pm 7.656 \dagger$ \\
pmol/L)/22.5] & & \\
Lipids & & \\
TG $(\mathrm{mmol} / \mathrm{L})$ & $0.324 \pm 0.027$ & $0.282 \pm 0.017$ \\
TC $(\mathrm{mmol} / \mathrm{L})$ & $3.264 \pm 0.143$ & $2.719 \pm 0.223$ \\
FFA $(\mathrm{mmol} / \mathrm{L})$ & $0.497 \pm 0.056$ & $0.496 \pm 0.024$ \\
WAT depot & & \\
DNA (ng/mg WAT) & $32.3 \pm 2.6$ & $49.6 \pm 5.2 \dagger$ \\
TG (ng/mg WAT) & $847.7 \pm 26.6$ & $876.7 \pm 8.2$ \\
TG/DNA & $29.3 \pm 3.2$ & $19.3 \pm 1.4 \dagger$ \\
Total DNA (ng/WAT depot) & $28.9 \pm 1.2$ & $29.3 \pm 3.5$ \\
\hline
\end{tabular}

$* n=12$ /group.

$\dagger p<0.05$ compared with CTRL.

\section{DISCUSSION}

The murine model used in this study provides an investigative tool for programming effects of nutrition during infancy and childhood on development of body composition and metabolism in a moderate obesogenic environment as present in many western and developing countries. Data on milk and erythrocyte FA profile confirmed that dietary FA supply to the pups changed according to maternal diet during lactation, and early diet intervention had a significant impact on tissue FA composition at weaning. Our study is the first to show lasting effects of fat quality of postnatal nutrition on adult body composition and metabolic homeostasis. Indeed, feeding of n-3 LCP for $40 \mathrm{~d}$ during postnatal development reduced body FM significantly. When subsequently challenged with a WSD in adolescence and adulthood, fat accumulation was reduced even more in mice previously fed with n-3 LCP compared with mice fed with CTRL diet. Therefore, n-3 LCP during postnatal development adjust metabolic responses to a WSD later in life and thus limit excessive body fat deposition during adulthood. 
Dietary DHA and ARA differentially affect early growth. In human, preterm infants dietary DHA reduced growth $(30,31)$, whereas addition of both DHA and ARA enhanced growth (31). Rat offspring fed with fish oil mainly consisting of n-3 LCP during both pregnancy and lactation had a reduced birth weight and decreased BW gain during lactation (32). In our mouse model, postnatal n-3 LCP reduced body fat before WSD challenge without significantly affecting LBM or BW gain. Reduced energy intake did not account for this reduction because energy density of the early diets was similar as was food intake in n-3 LCP and CTRL mice. We hypothesize that dietary n-3 LCP have altered adipocyte proliferation and differentiation in the postnatal period. In accordance with this hypothesis, n-3 LCP inhibit adipocyte differentiation in vitro and induce early apoptosis in obese rats $(33,34)$. Depotspecific effects of n-3 LCP have been demonstrated on expression of genes encoding for lipolytic and lipogenic proteins in rat WAT, which may specifically limit adipocyte hypertrophy of abdominal fat depots (35). Alternately, ARA and its metabolic products stimulate preadipocyte proliferation and adipogenesis (7).

Surprisingly, the effect of postnatal n-3 LCP on body composition did not subside after switching to a moderate obesogenic diet during adulthood. Postnatal n-3 LCP feeding actually decreased WSD-induced body fat accumulation by 29\% in adulthood compared with postnatal CTRL feeding.

The histological and biochemical analyses of WAT do not allow discerning between direct effects of the postnatal diet on PN42 and subsequent effect of the WSD. However, cell size distribution did show a shift toward smaller adipocytes due to early dietary n-3 LCP. This is in line with a decreased TG/DNA ratio suggesting less hypertrophic cells. Both groups had equal total DNA amounts per epididymal WAT depot. Therefore, programming effects of $n-3$ LCP on adipocyte number cannot be ruled out, because DNA content is determined by both adipocytes and cells of the stromal-vascular fraction. In conclusion, results of this study suggest that postnatal n-3 LCP affect development of WAT and give rise to sustained effects on adipocyte functionality during adulthood.

Postnatal n-3 LCP improve metabolic state and consequently may reduce susceptibility to metabolic diseases. Indeed, in addition to lowered body FM, insulin sensitivity was preserved and plasma lipid profile improved in adulthood. Similar direct and programming effects have been shown when n-3 LCP were provided during both pregnancy and lactation in rats (32). Moreover, postnatal dietary n-3 LCP also prevented hyperleptinemia and hypertension due to prenatal dexamethasone exposure (12). However, in this study, dietary n-3 LCP were provided from birth until the end of the study (6 mo later), which makes it difficult to discern between acute and programming effects of dietary n-3 LCP. The described protective effect may therefore not have persisted after diet discontinuation. In contrast, we show persisting effects of postnatal n-3 LCP even after 8 weeks of WSD, indicating that the period from birth up to childhood represents a critical time frame during which nutrition programs adult metabolism and body composition.
Consistent with reduced epididymal and inguinal fat depot weight and body FM, plasma leptin levels were significantly reduced by the n-3 LCP diet. No sustained effects on plasma levels of the other adipokines were identified except for IL-6. Either these levels were not affected by postnatal n-3 LCP or effects were abolished during WSD exposure. However, the lack of a dietary effect on adipokine levels measured systemically cannot exclude possible paracrine effects at tissue level (36).

Dietary n-3 LCP have anti-inflammatory properties and reduce proinflammatory ILs such as IL-6 in obese rats (37) and human subjects (38). High IL-6 levels have been correlated with high BMI, adiposity (39), and increased adipocyte size (40). Thus, higher plasma IL-6 at PN98 in n-3 LCP mice compared with CTRL is in clear contradiction with the reduced adiposity, smaller adipocytes, and the overall healthier metabolic profile with improved insulin sensitivity and plasma lipids.

To our knowledge, there are no programming studies available at present that could provide better understanding of the cause and consequence of the currently found increased adult IL-6 levels after postnatal n-3 LCP exposure. None of the other measured inflammatory adipokines were affected, suggesting that n-3 LCP feeding during infancy and childhood did not result in increased oxidative stress or inflammation in adulthood. Including analyses of IL-6 and other proinflammatory markers on tissue level in future studies may elucidate the origin and physiological significance of the higher systemically IL-6 levels found here.

Overall, we show the prevention of hypertrophic growth of epididymal adipose tissue by postnatal dietary n-3 LCP. The critical time frame of diet administration is emphasized by the persistence of effects despite an 8-week WSD exposure.

To our knowledge, we are the first to show lasting protective effects of modest FA composition changes in postnatal diet on excessive fat accumulation later in life. It is anticipated that even small alterations in postnatal nutrition offered during a critical time frame may be relevant for improving adult metabolic health. In addition, this experimental mouse model provides a useful tool to explore potential programming effects of postnatal dietary interventions and may help to identify the critical periods in postnatal metabolic development.

Acknowledgment. We thank Prof. Henriette DelemarreVan de Waal, Department of Pediatrics, Leiden University Medical Center, Leiden, The Netherlands, for reviewing this article.

\section{REFERENCES}

1. Berghöfer A, Pischon T, Reinhold T, Apovian CM, Sharma AM, Willich SN 2008 Obesity prevalence from a European perspective: a systematic review. BMC Public Health 8:200

2. Sturm R 2007 Increases in morbid obesity in the USA: 2000-2005. Public Health 121:492-496

3. Balakrishnan R, Webster P, Sinclair D 2008 Trends in overweight and obesity among 5-7-year-old White and South Asian children born between 1991 and 1999. J Public Health (Oxf) 30:139-144

4. Li C, Ford ES, Mokdad AH, Cook S 2006 Recent trends in waist circumference and waist-height ratio among US children and adolescents. Pediatrics 118:e1390-e1398

5. Willett WC, Leibel RL 2002 Dietary fat is not a major determinant of body fat. Am J Med 113:47S-59S 
6. Burdge GC, Calder PC 2006 Dietary alpha-linolenic acid and health-related outcomes: a metabolic perspective. Nutr Res Rev 19:26-52

7. Ailhaud G, Massiera F, Weill P, Legrand P, Alessandri JM, Guesnet P 2006 Temporal changes in dietary fats: role of $n-6$ polyunsaturated fatty acids in excessive adipose tissue development and relationship to obesity. Prog Lipid Res 45:203-236

8. Massiera F, Saint-Marc P, Seydoux J, Murata T, Kobayashi T, Narumiya S, Guesnet P, Amri EZ, Negrel R, Ailhaud G 2003 Arachidonic acid and prostacyclin signaling promote adipose tissue development: a human health concern? J Lipid Res 44:271279

9. Taylor PD, Poston L 2007 Developmental programming of obesity in mammals. Exp Physiol 92:287-298

10. Gluckman PD, Hanson MA, Cooper C, Thornburg KL 2008 Effect of in utero and early-life conditions on adult health and disease. N Engl J Med 359:61-73

11. Vickers MH, Gluckman PD, Coveny AH, Hofman PL, Cutfield WS, Gertler A Breier BH, Harris M 2005 Neonatal leptin treatment reverses developmental programming. Endocrinology 146:4211-4216

12. Wyrwoll CS, Mark PJ, Mori TA, Puddey IB, Waddell BJ 2006 Prevention of programmed hyperleptinemia and hypertension by postnatal dietary omega-3 fatty acids. Endocrinology 147:599-606

13. Roggero P, Gianni ML, Amato O, Orsi A, Piemontese P, Morlacchi L, Mosca F 2009 Is term newborn body composition being achieved postnatally in preterm infants? Early Hum Dev 85:349-352

14. Euser AM, Finken MJ, Keijzer-Veen MG, Hille ET, Wit JM, Dekker FW 2005 Associations between prenatal and infancy weight gain and BMI, fat mass, and fat distribution in young adulthood: a prospective cohort study in males and females born very preterm. Am J Clin Nutr 81:480-487

15. Ibáñez L, Ong K, Dunger DB, de Zegher F 2006 Early development of adiposity and insulin resistance after catch-up weight gain in small-for-gestational-age children. J Clin Endocrinol Metab 91:2153-2158

16. Martin-Gronert MS, Ozanne SE 2007 Experimental IUGR and later diabetes J Intern Med 261:437-452

17. Sullivan EL, Grove KL 2010 Metabolic imprinting in obesity. Forum Nutr 63:186194

18. Armitage JA, Taylor PD, Poston L 2005 Experimental models of developmental programming: consequences of exposure to an energy rich diet during development. J Physiol 565:3-8

19. Simoncíkova P, Wein S, Gasperikova D, Ukropec J, Certik M, Klimes I, Sebokova E 2002 Comparison of the extrapancreatic action of gamma-linolenic acid and n-3 PUFAs in the high fat diet-induced insulin resistance [Corrected]. Endocr Regul 36:143-149

20. Storlien LH, Jenkins AB, Chisholm DJ, Pascoe WS, Khouri S, Kraegen EW 1991 Influence of dietary fat composition on development of insulin resistance in rats. Relationship to muscle triglyceride and omega-3 fatty acids in muscle phospholipid. Diabetes 40:280-289

21. Halvorsen B, Rustan AC, Madsen L, Reseland J, Berge RK, Sletnes P, Christiansen EN 2001 Effects of long-chain monounsaturated and n-3 fatty acids on fatty acid oxidation and lipid composition in rats. Ann Nutr Metab 45:30-37

22. Flachs P, Rossmeisl M, Bryhn M, Kopecky J 2009 Cellular and molecular effects of n-3 polyunsaturated fatty acids on adipose tissue biology and metabolism. Clin Sci (Lond) 116:1-16

23. Helland IB, Smith L, Saarem K, Saugstad OD, Drevon CA 2003 Maternal supplementation with very-long-chain n-3 fatty acids during pregnancy and lactation augments children's IQ at 4 years of age. Pediatrics 111:e39-e44
24. Damsgaard CT, Lauritzen L, Kjaer TM, Holm PM, Fruekilde MB, Michaelsen KF, Frokiaer H 2007 Fish oil supplementation modulates immune function in healthy infants. J Nutr 137:1031-1036

25. Weisinger HS, Armitage JA, Sinclair AJ, Vingrys AJ, Burns PL, Weisinger RS 2001 Perinatal omega-3 fatty acid deficiency affects blood pressure later in life. Nat Med 7:258-259

26. Korotkova M, Gabrielsson BG, Holmang A, Larsson BM, Hanson LA, Strandvik B 2005 Gender-related long-term effects in adult rats by perinatal dietary ratio of n-6/n-3 fatty acids. Am J Physiol Regul Integr Comp Physiol 288:R575-R579

27. Reeves PG, Nielsen FH, Fahey GC Jr 1993 AIN-93 purified diets for laboratory rodents: final report of the American Institute of Nutrition ad hoc writing committee on the reformulation of the AIN-76A rodent diet. J Nutr 123:1939-1951

28. Levant B, Ozias MK, Carlson SE 2007 Diet (n-3) polyunsaturated fatty acid conten and parity affect liver and erythrocyte phospholipid fatty acid composition in female rats. J Nutr 137:2425-2430

29. Baur LA, O'Connor J, Pan DA, Wu BJ, O'Connor MJ, Storlien LH 2000 Relationships between the fatty acid composition of muscle and erythrocyte membrane phospholipid in young children and the effect of type of infant feeding. Lipids 35:77-82

30. Ryan AS, Montalto MB, Groh-Wargo S, Mimouni F, Sentipal-Walerius J, Doyle J, Siegman JS, Thomas AJ 1999 Effect of DHA-containing formula on growth of preterm infants to 59 weeks postmenstrual age. Am J Hum Biol 11:457-467

31. Innis SM, Adamkin DH, Hall RT, Kalhan SC, Lair C, Lim M, Stevens DC, Twist PF, Diersen-Schade DA, Harris CL, Merkel KL, Hansen JW 2002 Docosahexaenoic acid and arachidonic acid enhance growth with no adverse effects in preterm infants fed formula. J Pediatr 140:547-554

32. Siemelink M, Verhoef A, Dormans JA, Span PN, Piersma AH 2002 Dietary fatty acid composition during pregnancy and lactation in the rat programs growth and glucose metabolism in the offspring. Diabetologia 45:1397-1403

33. Kim HK, Della-Fera M, Lin J, Baile CA 2006 Docosahexaenoic acid inhibits adipocyte differentiation and induces apoptosis in 3T3-L1 preadipocytes. J Nut 136:2965-2969

34. Pérez-Matute P, Perez-Echarri N, Martinez JA, Marti A, Moreno-Aliaga MJ 2007 Eicosapentaenoic acid actions on adiposity and insulin resistance in control and high-fat-fed rats: role of apoptosis, adiponectin and tumour necrosis factor-alpha. Br J Nutr 97:389-398

35. Raclot T, Groscolas R, Langin D, Ferre P 1997 Site-specific regulation of gene expression by $\mathrm{n}-3$ polyunsaturated fatty acids in rat white adipose tissues. J Lipid Res 38:1963-1972

36. Wang P, Mariman E, Renes J, Keijer J 2008 The secretory function of adipocytes in the physiology of white adipose tissue. J Cell Physiol 216:3-13

37. Pérez-Echarri N, Perez-Matute P, Marcos-Gomez B, Baena MJ, Marti A, Martinez JA, Moreno-Aliaga MJ 2008 Differential inflammatory status in rats susceptible or resistant to diet-induced obesity: effects of EPA ethyl ester treatment. Eur J Nutr 47:380-386

38. Browning LM, Krebs JD, Moore CS, Mishra GD, O'Connell MA, Jebb SA 2007 The impact of long chain n-3 polyunsaturated fatty acid supplementation on inflammation, insulin sensitivity and CVD risk in a group of overweight women with an inflammatory phenotype. Diabetes Obes Metab 9:70-80

39. Khaodhiar L, Ling PR, Blackburn GL, Bistrian BR 2004 Serum levels of interleukin-6 and C-reactive protein correlate with body mass index across the broad range of obesity. JPEN J Parenter Enteral Nutr 28:410-415

40. Sopasakis VR, Sandqvist M, Gustafson B, Hammarstedt A, Schmelz M, Yang X, Jansson PA, Smith U 2004 High local concentrations and effects on differentiation implicate interleukin-6 as a paracrine regulator. Obes Res 12:454-460 